government and Tam Dalyell and Stephen Ross for the opposition. As well as protection for SSSIs, other controversial topics include the banning of shooting on Sundays, allowing bulls on public footpaths and how to maintain marine nature reserves.

Judy Redfearn

\section{Reagan's cuts}

\section{Handler objects}

\section{Washington}

Dr Philip Handler, in his farewell address last week as president of the National Academy of Sciences, came close to accusing the National Science Board of cowardice in its failure to protest at the Reagan Administration's cut in the budget of the National Science Foundation (NSF).

The proposal is that the foundation's budget for 1982 be trimmed to $\$ 1,033$ million, more than 30 per cent less than $\mathrm{Mr}$ Carter's request for $\$ 1,353$ million. At its meeting in March, the board, which is formally responsible for the activities of NSF, approved a statement on the cuts in which it complained that it had been excluded from the budget decision.

The statement also mentioned "problems of serious concern" such as the need to upgrade university research equipment and its "limited capability to reprogram funds to take advantage of emerging research opportunities". There is, however, no direct criticism of the Reagan Administration's decision as such.

Dr Handler said plaintively last week "Would that that statement were not quite so subtle". Handler accepts that the board is constrained by its formal place within the Administration, but he told the academy that the board members' "statutory responsibility to establish the priorities and allocate resources had, in fact, been usurped". And he added: "In not saying so, in unequivocal language, they may allow this incident to become a precedent"'

Handler admitted that for the members of the board to have been more forthrigh might have meant a confrontation with the Administration in which the National Science Foundation would be the loser. "But in crafting a statement in which protest is to be found only by sophisticated reading between the lines ... the board seemed to be party to the actions of the Office of Management and Budget."

Handler also quoted the board's contention that it was difficult to be engaged in policy decisions about budget cuts in the light of the "economic emergency", which precluded the normal discussion with the board of NSF priorities. "Emergency? What emergency?" asked Handler. "The fact that NSF was given but 24 hours, when the board was not in town, to defend its right to support social science and science education, inter alia, is preposterous."

David Dickson
Nuclear power in Yugoslavia Staying independent

\section{Belgrade}

Core loading is now under way at Yugoslavia's first nuclear power station in Krsko. Formally, the station - based on a Westinghouse light-water reactor - is years behind schedule, but this is in part due to an over-optimistic target of five years for construction.

The station has been built jointly by the republics of Slovenia and Croatia. The leading physics institutes of the two republics, the Rudjer Boskovic Institute (Zagreb) and the Josef Stefan Institute (Ljubljana), have been training staff for the new station while building was being completed, and working out the final safety report for the reactor.

Yugoslavia's commitment to nuclear power is strengthened by the presence of uranium deposits at Zirovski Vrh in Slovenia. There are few dissenting voices, notably hotel-keepers on the Dalmatian coast objecting to the proposed siting of the country's second reactor near the tourist resorts, and veteran anti-nuclear campaigner Dr Ivan Supek. Most Yugoslavs apparently see nuclear power as a way to greater energy self-sufficiency.

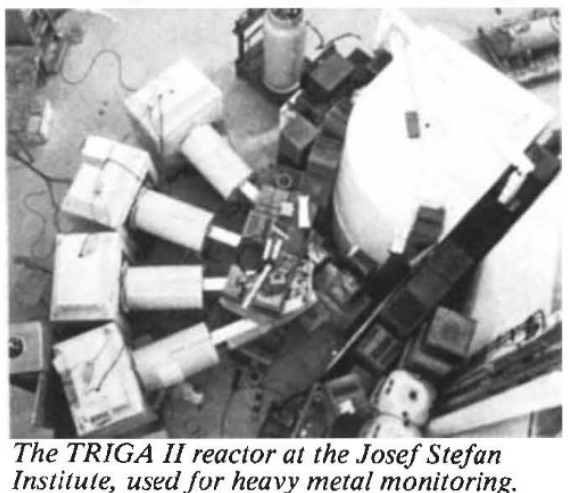

Before uranium mining and milling operations begin, however, a group from the Josef Stefan Institute is making a detailed survey of background radiation in the area. And this survey forms part of an international project to map the radioecology of the Danube basin.

Also being measured in the survey are heavy metal trace elements, including cadmium, arsenic and mercury. The area has a history of mercury mining and once the price of mercury picks up again the old mine is likely to be reopened. The mine closed in the mid-1970s and there is evidence of considerable mercury poisoning in the mine-workers involved. But studies of the effects of mining are being hampered by shortage of finance for a much-needed survey of the non-mining population in the mining area.

This highlights a general shortage of funds for research in Yugoslavia. There is no longer any central planning of science, and funds come either from direct contracts with industry, or else from a
Proton decay hunt

\section{New Delhi}

Indian and Japanese physicists have discovered three "candidate" proton decay events in a massive iron detector system set up 2,300 metres underground in the Kolar gold mines $100 \mathrm{~km}$ north of Bangalore in South India. Begun nearly five months ago, the experiment is to last two years during which at least six of these rare events are expected to be observed provided the proton lifetime does not exceed $10^{31}$ years.

The detector system consists of 140 tonnes of iron: 100 tonnes for the detector elements and the remainder for shielding. The detector elements are $4 \mathrm{~m}$ and $6 \mathrm{~m}$ long iron tubes of cross-section $10 \mathrm{~cm} \times 10 \mathrm{~cm}$. The 1,650 proportional counters are stacked to make a giant 35 -layer cake that is $6 \mathrm{~m}$ long, $4 \mathrm{~m}$ wide and $4 \mathrm{~m}$ tall.

The on-line electronics system and the detector configuration enable the total energy of the decay process, the decay vertex and a three-dimensional plot of the tracks of decay products to be obtained. There are some $10^{32}$ nucleons in the iron and assuming a detector efficiency of 50 per cent, it is hoped to reach a proton lifetime limit of $5 \times 10^{31}$ years.

The main background to the decay events comes from cosmic rays. Neutrinos and some muons created in cosmic ray events in the atmosphere can penetrate down to the detector; but the Kolar equipment is so deep most of the muons are absorbed in the rock above. Nevertheless, by the end of last week Kolar had recorded 223 vertical muons; 8 horizontal muons, probably coming from neutrino interactions in the rock beside the detector; three neutrino events in the detector; and three events which so far can be explained in no other way than as proton decays. However, all three events have a track which reaches (or emanates from) the edge of the chamber, so they may yet be false events, mimicked by a particle entering the chamber from outside. If the events are confirmed, the corresponding proton lifetime would be $1-3 \times 10^{30}$ years, around the number being predicted by theories which unify the weak, electromagnetic and strong interactions into one grand "gauge theory with spontaneous symmetry breaking".

K.S. Jayaraman

structure of "Self-Management Communities of Interest for Science", which administer funds voted from profits of individual commercial enterprises.

The Josef Stefan Institute gets 40 per cent of its funds from the Slovenian assembly of such communities and 60 per cent from contracts. But neither source has shown much interest in studying mercury levels in their region and monitoring a control population elsewhere. Vera Rich 